\title{
Polymer Topology Determines the Formation of Protein Corona on Core-Shell Nanoparticles
}

\author{
Martina Schroffenegger, ${ }^{\S}$ Nikolaus S. Leitner, ${ }^{\S}$ Giulia Morgese, Shivaprakash N. Ramakrishna, \\ Max Willinger, Edmondo M. Benetti,* and Erik Reimhult*
}

Cite This: ACS Nano 2020, 14, 12708-12718

Read Online

ACCESS | Llll Metrics \& More | 国 Article Recommendations | st Supporting Information
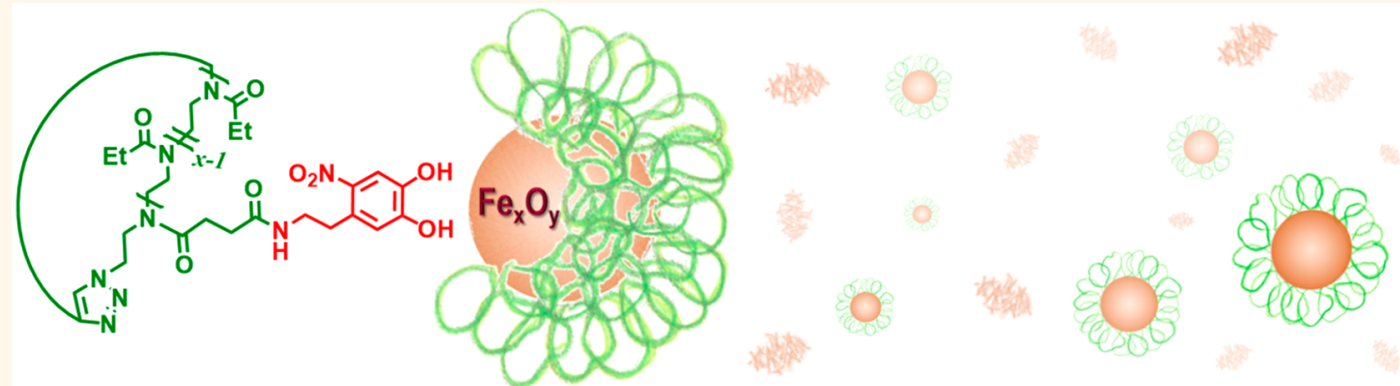

ABSTRACT: Linear and cyclic poly(2-ethyl-2-oxazoline) (PEOXA) adsorbates provide excellent colloidal stability to superparamagnetic iron oxide nanoparticles $\left(\mathrm{Fe}_{x} \mathrm{O}_{y} \mathrm{NPs}\right)$ within protein-rich media. However, dense shells of linear PEOXA brushes cannot prevent weak but significant attractive interactions with human serum albumin. In contrast, their cyclic PEOXA counterparts quantitatively hinder protein adsorption, as demonstrated by a combination of dynamic light scattering and isothermal titration calorimetry. The cyclic PEOXA brushes generate NP shells that are denser and more compact than their linear counterparts, entirely preventing the formation of a protein corona as well as aggregation, even when the lower critical solution temperature of PEOXA in a physiological buffer is reached.

KEYWORDS: inorganic nanoparticles, poly(2-oxazoline), protein corona, protein adsorption, isothermal titration calorimetry, polymer brushes, cyclic polymers

$\mathrm{W}$ hen nanoparticles (NPs) are applied in the biomedical field, they must exhibit low attractive interactions with biomolecules and high stability in complex biological fluids to fulfill their functions. ${ }^{1,2}$ Formation of a protein corona is thought to lead to a loss in colloidal stability, and to clearance in vivo due to aggregation and recognition by the immune system. ${ }^{3-6}$ A well-established strategy to hinder protein adsorption and provide steric stabilization to NPs relies on their functionalization with hydrophilic organic ligands. Theoretical and experimental studies of how the properties of nanoparticle shells influence the formation of the protein corona and interaction with serum proteins have concluded that preventing the formation of hydrophobic contacts by a hydrophilic shell is required to avoid the creation of a protein corona. ${ }^{7,8}$ That hydrophilicity is a necessary but not sufficient criterion is shown by studies on monolayer-coated nanoparticles. ${ }^{9-11}$ For example, whereas it was suggested that zwitterionic hydrophilic monolayer coatings are more effective than charged or uncharged hydrophilic oligomers, ${ }^{11}$ they still only reduced rather than completely suppressed protein corona adsorption. ${ }^{12}$ Thus, in practical applications, the by far dominating strategy to achieve longterm stability in biofluids or circulation times in vivo has been to form thick, highly hydrated, and densely grafted polymer shells, so-called "polymer brush" shells. ${ }^{13-15}$ A recent perspective article summarizing lessons learned by a decade of research on the NP protein corona by Caruso et al. suggested that, while grafting of hydrophilic polymers to

Received: March 19, 2020

Accepted: August 31, 2020

Published: August 31, 2020 
nanoparticles is the leading strategy to create "stealth" particles, their interactions are convoluted with those of the core, and their architecture can influence protein adsorption and vice versa. ${ }^{16}$

It was early shown using isothermal titration calorimetry (ITC) that the density of the polymer chains on the nanoparticle surface influences the affinity of serum proteins such as albumin to the surface, which in these studies was related to the overall hydrophilicity of the particle. ${ }^{17}$ In other words, the grafting stability and grafting density $(\sigma)$ of the polymer brush shell determine the reduction of nonspecific protein adsorption, which strongly correlates with the suppression of receptor-mediated endocytosis by cells as well as recognition by phagocytes. ${ }^{14,18,19}$

Poly(ethylene glycol) (PEG) represents the most commonly applied polymer to generate "stealth" shells on NPs. ${ }^{16,18}$ At relatively low values of $\sigma\left(<0.16\right.$ chains $\left.\mathrm{nm}^{-2}\right)$, the uptake of PEG brush-bearing Au NPs by macrophages was found to be dependent on the presence of adsorbed proteins, whereas at $\sigma$ $>0.64$ chains $\mathrm{nm}^{-2}$, no correlation between these two processes could be highlighted. ${ }^{13}$ This result led to the interpretation of the NPs' fate within physiological environments as directly correlated to the amount and type of proteins physisorbed on their shells. Parak and co-workers recently demonstrated that hindering of nonspecific protein adsorption on NPs functionalized with PEG grafts led to a significant reduction in the uptake by murine fibroblasts. ${ }^{20}$ Similarly, Schöttler et al. recorded how clusterin proteins adsorbed from serum on NPs with hydrophilic polymer shells significantly reduced internalization by macrophages. ${ }^{21}$ In these reports, a relatively low density of PEG was grafted on the surface of the NPs, and thus nonspecific protein physisorption could not entirely be prevented.

We recently identified a value of $\sigma$ for bioinert polymers of $\sim 1$ chain $\mathrm{nm}^{-2}$ as the threshold to prevent phagocytosis of NPs with diameters $<20 \mathrm{~nm} .^{19,22,23}$ However, recent studies from our group highlighted that even these densely grafted PEG and poly(2-alkyl-2-oxazoline) (PAOXA) brushes could not quantitatively prevent the association of albumin from serum on core-shell NPs. ${ }^{14}$ Some protein adsorption always took place either at the interface of the polymer shell or within the curved brush structure. ${ }^{20}$ Given the previous research in the field described above, cell internalization, as well as colloidal stability, should be strongly correlated to the characteristics of the protein corona formed on hybrid NPs. A polymer shell that completely suppresses any corona formation in contact with serum proteins could be a game changer but has not been proposed yet. ${ }^{6}$ If this objective were to be achieved, the interaction between biomolecules and engineered shells could be simultaneously controlled in a precise manner and enable many more applications in medicine and biotechnology. With this objective in mind, we turned our attention to cyclic polymers. We applied them in the form of functional adsorbates to generate ultradense, completely protein-repellent brush shells on inorganic NPs.

The assembly of densely grafted brushes on NPs using linear polymer ligands suffers from an intrinsic limitation, which is determined by the steric hindrance between adsorbing grafts. Thus, relatively small serum proteins with flexible domains, like albumin, can partially unfold and penetrate within linear brushes that are characterized by a density that is not sufficient to prevent protein intercalation. In addition, nonspecific interactions between biomolecules and linear brush chain ends can still take place, triggering the formation of a loosely associated soft protein corona. ${ }^{24,25}$

In contrast, cyclic polymer adsorbates feature smaller molecular dimensions with respect to their linear analogues of comparable molar mass, due to the steric constraints introduced during cyclization, ${ }^{26,27}$ and thus they are capable of assembling on macroscopic and high-aspect-ratio surfaces, yielding much denser and more compact brushes. ${ }^{15,28}$ Especially when applied on inorganic NPs, we recently demonstrated that cyclic PAOXA adsorbates generate an ultradense brush shell, which can substantially improve colloidal stability, also within protein dispersions. ${ }^{15}$

Stimulated by these findings, here, we systematically demonstrate that shifting the topology of poly(2-ethyl-2oxazoline) (PEOXA) adsorbates from linear to cyclic results in the formation of brush shells with an increased effective chain density and steric repulsion close to the NP core. These structural properties improve the stability of superparamagnetic iron oxide $\left(\mathrm{Fe}_{x} \mathrm{O}_{y}\right)$ NPs and yield a quantitatively demonstrated total suppression of adsorption of human serum albumin (HSA). Albumin is a suitable first protein to test, as it is most challenging to suppress its adsorption as well as it being the most abundant protein in serum. ${ }^{9,10,17}$

\section{RESULTS AND DISCUSSION}

The polymer-grafted nanoparticles were synthesized, purified, and characterized as described in detail in the Experimental Methods. In brief, first, linear and cyclic PEOXA adsorbates (L-PEOXA and C-PEOXA) with $M_{\mathrm{n}}$ of $\sim 10 \mathrm{kDa}$ were synthesized by cationic ring-opening polymerization (CROP) ${ }^{29}$ followed by postmodification. In particular, CPEOXA were obtained from $\alpha$-alkyne- $\omega$-azide PEOXA linear precursors using a ring-closure strategy through $\mathrm{Cu}^{\mathrm{I}}$-catalyzed Huisgen cycloaddition. $^{30,31}$ Both L- and C-PEOXA were subsequently derivatized with nitrodopamine, which was previously shown to act as a strong anchoring group for the functionalization of metal oxide surfaces. ${ }^{32,33}$ A schematic of the polymer synthesis and functionalization is provided in Scheme S1, with ${ }^{1} \mathrm{H}$ NMR, Fourier transform infrared (FTIR), and size exclusion chromatography (SEC) data of the products presented in the Supporting Information (Figures S1-S6).

The functionalized PEOXA was grafted to monodisperse oleic-acid-coated $\mathrm{Fe}_{x} \mathrm{O}_{y}$ NPs via direct ligand exchange in dimethylformamide (DMF). The resulting L-PEOXA-Fe $\mathrm{O}_{y}$ and C-PEOXA-Fe $\mathrm{O}_{y}$ core-brush shell NPs were carefully purified from excess ligand by precipitation and dialysis. ${ }^{34-36}$ The size and composition, including the grafting density $\sigma$, of the NPs were subsequently characterized by a combination of transmission electron microscopy (TEM, Figure S7), dynamic light scattering (DLS, Figure S8), SEC (Figure S6), and thermogravimetric analysis (TGA, Figure S9). The results are summarized in Table 1.

Both L-PEOXA-Fe $\mathrm{O}_{y}$ and C-PEOXA-Fe $\mathrm{O}_{y}$ NPs exhibit excellent colloidal stability in (4-(2-hydroxyethyl)-1-piperazineethanesulfonic acid) (HEPES) buffer solution at $\mathrm{pH}$ 7.4, with C-PEOXA- $\mathrm{Fe}_{x} \mathrm{O}_{y}$ NPs showing a hydrodynamic diameter $\left(D_{\mathrm{H}}\right)$ smaller than that of their L-PEOXA- $\mathrm{Fe}_{x} \mathrm{O}_{y}$ analogues (Figure S8). The values of $D_{\mathrm{H}}$ for L-PEOXA-Fe $\mathrm{O}_{y}$ and CPEOXA-Fe $\mathrm{O}_{y}$ NPs (Table 1) were constant over time. They did not show significant variations while increasing the temperature up to the critical solution temperature (CST) of PEOXA in HEPES buffer solution $\left(60-64{ }^{\circ} \mathrm{C}\right.$, Supporting Information). Interestingly, there was not a marked difference 
Table 1. Structural Properties of L-PEOXA-Fe $\mathrm{O}_{y}$ and CPEOXA-Fe ${ }_{x} \mathrm{O}_{y} \mathrm{NPs}$

$\begin{array}{ccccc}\text { sample } & \begin{array}{c}\text { core diameter } \\ (\mathrm{nm})\end{array} & \begin{array}{c}M_{\mathrm{n}}{ }^{b} \\ (\mathrm{kDa})\end{array} & \begin{array}{c}\sigma^{c} \\ \left(\mathrm{~nm}^{-2}\right)\end{array} & D_{\mathrm{H}}{ }^{d}(\mathrm{~nm}) \\ \mathrm{L}^{2}-\mathrm{PEOXA}-\mathrm{Fe}_{x} \mathrm{O}_{y} & 8.9 \pm 0.6 & 10.0 & 1.0 & 52.5 \pm 0.8 \\ \text { C-PEOXA-Fe } \mathrm{O}_{y} & 8.9 \pm 0.6 & 10.2 & 1.6 & 21.9 \pm 2.3\end{array}$

${ }^{a}$ Measured by TEM. ${ }^{b}$ Measured by SEC. ${ }^{c}$ Estimated from TGA and TEM data. ${ }^{d}$ Measured by DLS in HEPES buffer solution, using mean values and standard deviations from number-weighted distributions.

in the CST recorded for topologically different PEOXA shells (Figure S8).

The value of $\sigma$ measured for the cyclic brush shells was substantially higher than what was obtained for the linear brush shells, reaching 1.6 chains $\mathrm{nm}^{-2}$. It is also important to emphasize that this value does not take into account the intrinsic conformation of cyclic adsorbates grafted on the $\mathrm{Fe}_{x} \mathrm{O}_{y}$ surface. Two polymer segments extend from the surface for each graft and close in a loop at the brush shell interface. Thus, the effective polymer chain density exceeds 3 chains $\mathrm{nm}^{-2}$ and reaches a value among the highest ever measured for core-polymer shell NPs. ${ }^{37}$
The ultradense and highly compact structure of the cyclic brush shells is a direct consequence of the reduced molecular dimensions characterizing C-PEOXA adsorbates. Their compact conformation determines a smaller footprint during grafting compared to linear adsorbates, ${ }^{38,39}$ and therefore, generates a denser and thinner brush shell. ${ }^{39,40}$ Although we have no direct measure of the polymer shell structure by these techniques, it is clear that a thinner and much denser shell results from grafting cyclic PEOXA to the NP surface than for linear PEOXA. Thus, direct access to the surface for shortrange binding interactions will be strongly suppressed for NPs grafted with C-PEOXA brushes.

TEM and high-resolution atomic force microscopy (AFM) were used to characterize the morphology of the NPs with topologically different PEOXA shells (Figure 1). TEM micrographs using background staining to visualize the PEOXA shell (the light area marked with red arrows around the dark cores marked with blue arrows) confirmed the presence of a thinner, more compact shell around C-PEOXA$\mathrm{Fe}_{x} \mathrm{O}_{y}$ NPs than around L-PEOXA-Fe $\mathrm{O}_{y}$ (Figure 1a,b). The cores of both types of particles are well-separated even after drying on the grid. However, the organization of the $\mathrm{C}$ PEOXA- $\mathrm{Fe}_{x} \mathrm{O}_{y} \mathrm{NPs}$ in quasi-lattices after drying also suggests
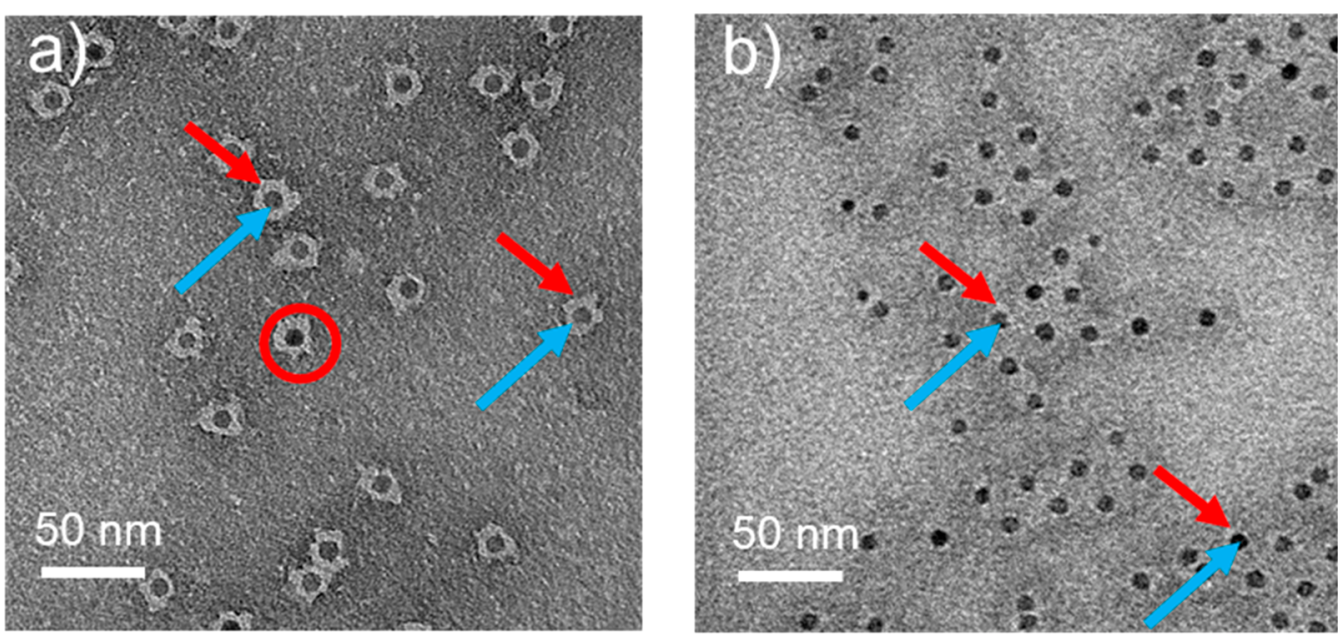
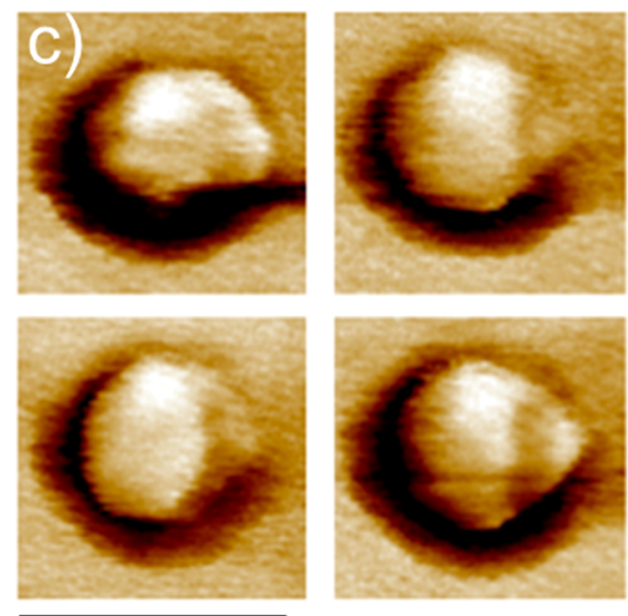

$50 \mathrm{~nm}$
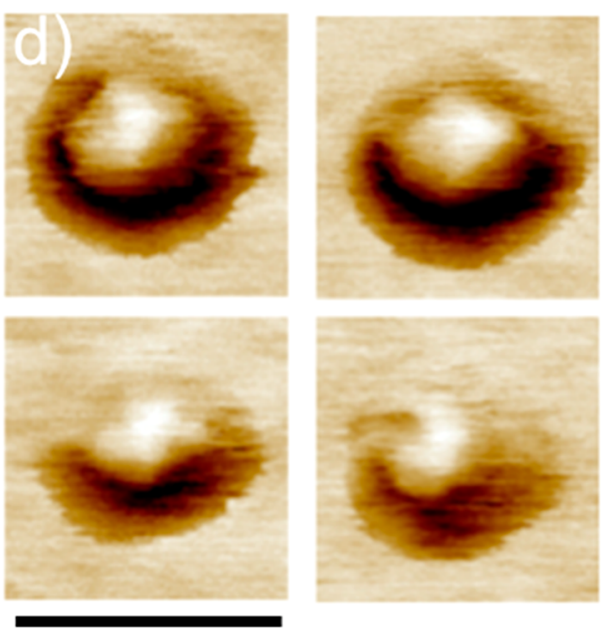

$50 \mathrm{~nm}$

Figure 1. TEM micrographs of (a) L-PEOXA-Fe $\mathrm{O}_{y}$ and (b) C-PEOXA-Fe $\mathrm{O}_{y}$ NPs. High-resolution AFM phase-contrast micrographs recorded on (c) L-PEOXA-Fe $\mathrm{O}_{y}$ and (d) C-PEOXA-Fe $\mathrm{O}_{y}$ NPs. The red arrows indicate the lighter, unstained PEOXA shell of the particles, and the blue arrows indicate the high-contrast $\mathrm{Fe}_{x} \mathrm{O}_{y}$ core. 
that the thin shells are dense and do not interpenetrate. Only monodisperse nanoparticles with dense and rigid shells, such as oleate, typically form monolayer crystals after being spread on

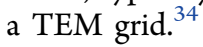

We used AFM to additionally highlight the differences in grafted polymer shell extension and density. Figure $1 \mathrm{c}, \mathrm{d}$ compares phase-contrast micrographs recorded by AFM in air. The representative micrographs of L-PEOXA- $\mathrm{Fe}_{x} \mathrm{O}_{y}$ and CPEOXA-Fe $\mathrm{O}_{y}$ show that the C-PEOXA- $\mathrm{Fe}_{x} \mathrm{O}_{y}$ nanoparticles have a smaller total size even though the inorganic cores are identical and that the C-PEOXA-Fe $\mathrm{O}_{y}$ nanoparticles have a higher grafting density. This implies that the C-PEOXA-Fe $\mathrm{O}_{y}$ polymer shells are denser than those of L-PEOXA-Fe $\mathrm{O}_{y}$.

TEM and AFM require imaging after drying that can distort the strongly hydrated polymer shell of the NPs. The drying makes the measured sizes not directly comparable to the hydrodynamic size of the particles. Therefore, we also performed force versus separation $(F-S)$ measurements on linear and cyclic polymer brushes grafted to planar $\mathrm{TiO}_{2}-$ coated surfaces and a similarly coated colloidal probe AFM tip to quantify differences in polymer brush thickness and repulsion (Figure 2).

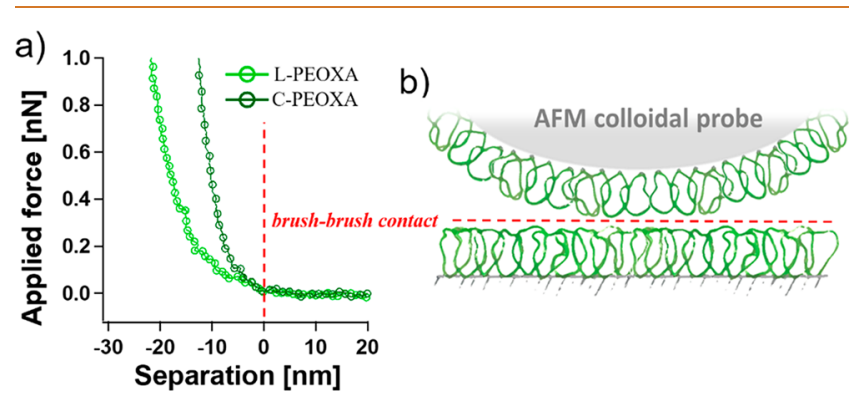

Figure 2. (a) Force versus separation profiles recorded by colloidal probe AFM by compressing L-PEOXA and C-PEOXA brushes as schematically shown in (b).

By applying the same polymer-grafting conditions used to functionalize $\mathrm{Fe}_{x} \mathrm{O}_{y} \mathrm{NPs}$, we obtained "planar" brushes presenting dry thicknesses $\left(d_{\text {dry }}\right)$ of $4.7 \pm 0.2$ and $5.4 \pm 0.1$ $\mathrm{nm}$ and $\sigma$ of 0.32 and 0.36 chains $\mathrm{nm}^{-2}$ for L-PEOXA and CPEOXA, respectively (measured by variable angle spectroscopic ellipsometry, VASE). The lower grafting densities observed on planar rather than on the highly curved NP surfaces are due to the bigger steric constraint during grafting on planar surfaces. ${ }^{18}$ L-PEOXA and C-PEOXA brushes were subsequently compressed using colloidal AFM probes functionalized with topologically identical PEOXA assemblies while recording $F-S$ profiles (Figure $2 b$ ). As highlighted in Figure $2 \mathrm{a}$, the approach $F-S$ curves generated on C-PEOXA films showed a significantly steeper profile at separations shorter than the contact distance of the opposing brush surfaces, compared to those recorded on L-PEOXA analogues. This strongly implies a denser and more compact morphology of C-PEOXA brushes, which show a "stiffer" and more impenetrable character compared to their linear counterparts. The higher stiffness, density, and lower chain interpenetration should also translate into stronger steric repulsion of other particles and polymers, such as proteins, as generally accepted for repulsive polymer brushes.

Having determined the structural properties and colloidal stability of the different core-PEOXA brush shell NPs, we subsequently investigated their interaction with HSA, the most abundant and one of the strongest adsorbing biomolecules present in human serum. $6,10,41$

HSA was progressively added to suspensions of L-PEOXA$\mathrm{Fe}_{x} \mathrm{O}_{y}$ and C-PEOXA-Fe $\mathrm{O}_{y}$ NPs. DLS recorded the hydrodynamic diameter, $D_{\mathrm{H}}$, following the sequential addition of increasing amounts of protein. In parallel, ITC was employed on the same dispersions to quantitatively determine the thermodynamic parameters describing the interaction between the NPs and HSA. The combination of DLS and ITC to investigate $\mathrm{NP}$-protein interactions has been used previously by us and others, ${ }^{9,10,14}$ as complementary techniques that shed light on both the thermodynamic parameters of protein corona formation and resulting aggregation.

The evolution of the number-weighted $D_{\mathrm{H}}$ of L-PEOXA$\mathrm{Fe}_{x} \mathrm{O}_{y}$ and C-PEOXA- $\mathrm{Fe}_{x} \mathrm{O}_{y}$ NPs with an increasing concentration of HSA is presented in Figure 3. The corresponding DLS correlation curves are shown in Figure S10, and the full set of intensity and number-weighted DLS curves are shown in Figure S11. The values of $D_{\mathrm{H}}$ for L-PEOXA-Fe $\mathrm{O}_{y}$ NPs remained nearly constant upon increasing the content of HSA in the dispersion. A second peak at lower $D_{\mathrm{H}}$ values corresponding to HSA was only spuriously observed as an artifact (Figure 3a). In contrast, dispersions of C-PEOXA$\mathrm{Fe}_{x} \mathrm{O}_{y}$ showed the manifest presence of a second signal, corresponding to lower values of $D_{\mathrm{H}}$ and ascribed to free HSA, which progressively dominated the DLS spectrum with increasing protein concentration (Figure $3 b$ ).

We rationalize the qualitatively different behaviors displayed by NPs with topologically distinguishable PEOXA shells
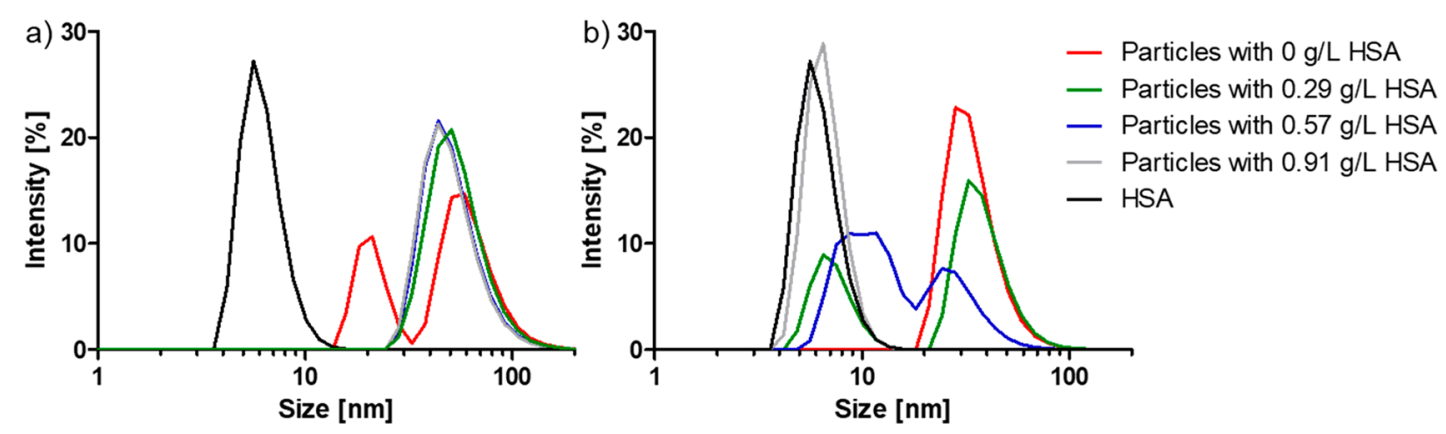

Figure 3. Number-weighted $D_{\mathrm{H}}$ measured by DLS on (a) L-PEOXA-Fe $\mathrm{O}_{y}$ and (b) C-PEOXA-Fe $\mathrm{O}_{y}$ NP dispersions in HEPES buffer solution $\left(0.5 \mathrm{~g} \mathrm{~L}^{-1}\right)$ upon the addition of increasing amounts of HSA. Three measurements were performed after 10 min of incubation for every HSA concentration: $0 \mathrm{~g} \mathrm{~L}^{-1} \mathrm{HSA}$ (red), $0.29 \mathrm{~g} \mathrm{~L}^{-1} \mathrm{HSA}$ (green), $0.57 \mathrm{~g} \mathrm{~L}^{-1} \mathrm{HSA}$ (blue), $0.91 \mathrm{~g} \mathrm{~L}^{-1} \mathrm{HSA}$ (gray), and dispersion of only $1.0 \mathrm{~g} \mathrm{~L}^{-1}$ HSA (black). The HSA peak is distinguishable for C-PEOXA-Fe $\mathrm{O}_{y}$ NP but not for L-PEOXA-Fe $\mathrm{O}_{y}$. 

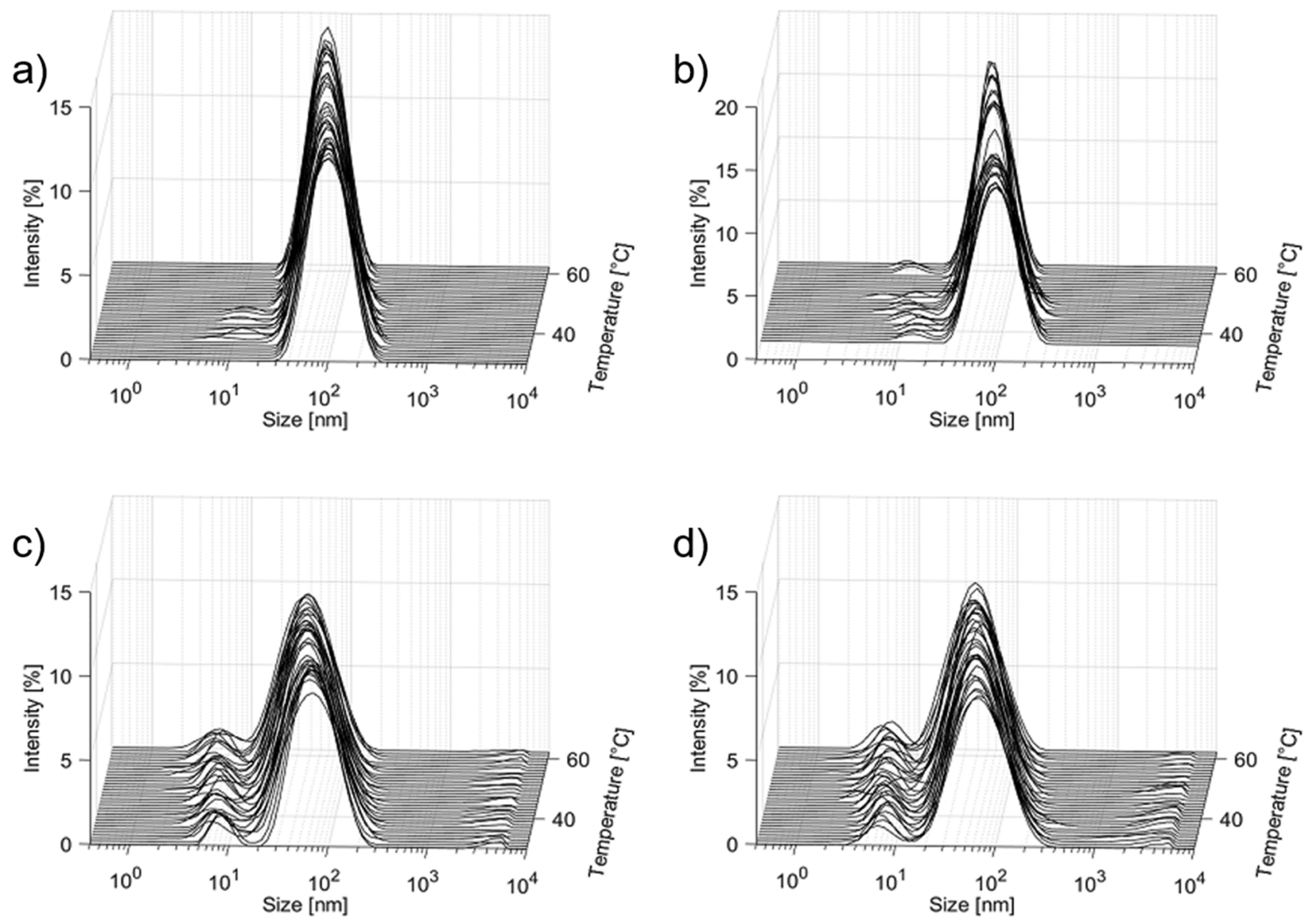

Figure 4. Intensity-weighted $D_{\mathrm{H}}$ recorded by DLS on $0.5 \mathrm{~g} \mathrm{~L}^{-1}$ dispersions of (a,b) L-PEOXA-Fe $\mathrm{O}_{y}$ and (c,d) C-PEOXA-Fe $\mathrm{O}_{y}$ NPs containing $0.91 \mathrm{~g} \mathrm{~L}^{-1}$ of HSA. Heating and cooling ramps are reported in $(\mathrm{a}, \mathrm{c})$ and $(\mathrm{b}, \mathrm{d})$, respectively.

dispersed with HSA by considering two factors. First, the algorithm used to calculate size distributions of particle mixtures with similar size from DLS data requires well-defined and narrowly dispersed populations to resolve them as distinct distributions. Second, DLS is much more sensitive to large objects because the scattered light intensity scales approximately as $R^{6}$ (with $R$ corresponding to the radius of the scattering object). The scattering signal originating from relatively large objects, such as aggregates, easily swamps the signal generated by small proteins, which then becomes invisible in the DLS histogram. Proteins associated with particles or aggregating particles, therefore, lead to the formation of larger objects, whose scattering signal "masks" the presence of other smaller biomolecules present in the dispersion. This is probably the case of L-PEOXA- $\mathrm{Fe}_{x} \mathrm{O}_{y} \mathrm{NPs}$, where the linear brush shell, although densely grafted, cannot completely prevent association with HSA, leading to the formation of NP-protein aggregates. This is in agreement with previous investigations by DLS of protein interaction with densely grafted polymer brush shell nanoparticles, which show colloidal stability but for which the proteins cannot be distinguished. ${ }^{19,37}$ In contrast, an increase in hydrodynamic size is typically observed for small nanoparticles with monolayer shells of hydrophilic ligands, which offer less protection from the formation of a protein corona. ${ }^{9,10}$ The pure L-PEOXA- $\mathrm{Fe}_{x} \mathrm{O}_{y}$ NPs are already large and possibly more polydisperse than the C-PEOXA-Fe $\mathrm{O}_{y}$ NPs, and their signal swamps that of the free HSA.

However, DLS data can clearly distinguish C-PEOXA-Fe $\mathrm{O}_{y}$ NPs from HSA across the entire range of tested protein concentrations. It indicates the presence of two extremely monodisperse particle populations (HSA and C-PEOXA-Fe $\mathrm{O}_{y}$ NPs) that do not interact. This is aided by the overall smaller particle size and it is a strong indication of negligible interaction between C-PEOXA- $\mathrm{Fe}_{x} \mathrm{O}_{y} \mathrm{NPs}$ and HSA.

Dispersions of $0.5 \mathrm{~g} \mathrm{~L}^{-1}$ L-PEOXA-Fe $\mathrm{O}_{y}$ and C-PEOXA$\mathrm{Fe}_{x} \mathrm{O}_{y}$ NPs containing $0.91 \mathrm{~g} \mathrm{~L}^{-1}$ of HSA were subsequently heated until reaching the CST of the polymer, just above 60 ${ }^{\circ} \mathrm{C}$ (cf. Figure S8), while simultaneously monitoring the characteristics of the mixture by DLS (Figure 4). The evolution of the intensity-weighted $D_{\mathrm{H}}$ histograms demonstrates that both L-PEOXA-Fe $\mathrm{O}_{y}$ and C-PEOXA-Fe $\mathrm{O}_{y}$ NPs were characterized by excellent colloidal stability across the temperature range tested. Relevantly, the values of $D_{\mathrm{H}}$ for CPEOXA-Fe $\mathrm{O}_{y}$ NPs were stable and always distinguishable with respect to the peak correlated to the protein population, both during the heating (Figure 4c) and cooling ramps (Figure $4 d$ ). In addition, $D_{\mathrm{H}}$ slightly but progressively decreased with increasing the temperature, due to the partial dehydration of the C-PEOXA brush shells. The relatively high concentration of HSA did not interfere with the partial shrinkage of CPEOXA shells; that is, the formation of a protein corona did not occur, even at temperatures similar to the CST of the brushes. Upon the dispersions being cooled to $37{ }^{\circ} \mathrm{C}$, the original values of $D_{\mathrm{H}}$ were recovered both for L-PEOXA- $\mathrm{Fe}_{x} \mathrm{O}_{y}$ and C-PEOXA-Fe $\mathrm{O}_{y}$ NPs.

The thermodynamic parameters associated with the nonspecific binding interactions between core-PEOXA shell NPs and HSA were determined by ITC. By this technique, the dissociation constant $\left(K_{\mathrm{D}}\right)$, Gibbs free energy $(\Delta G)$, enthalpy 

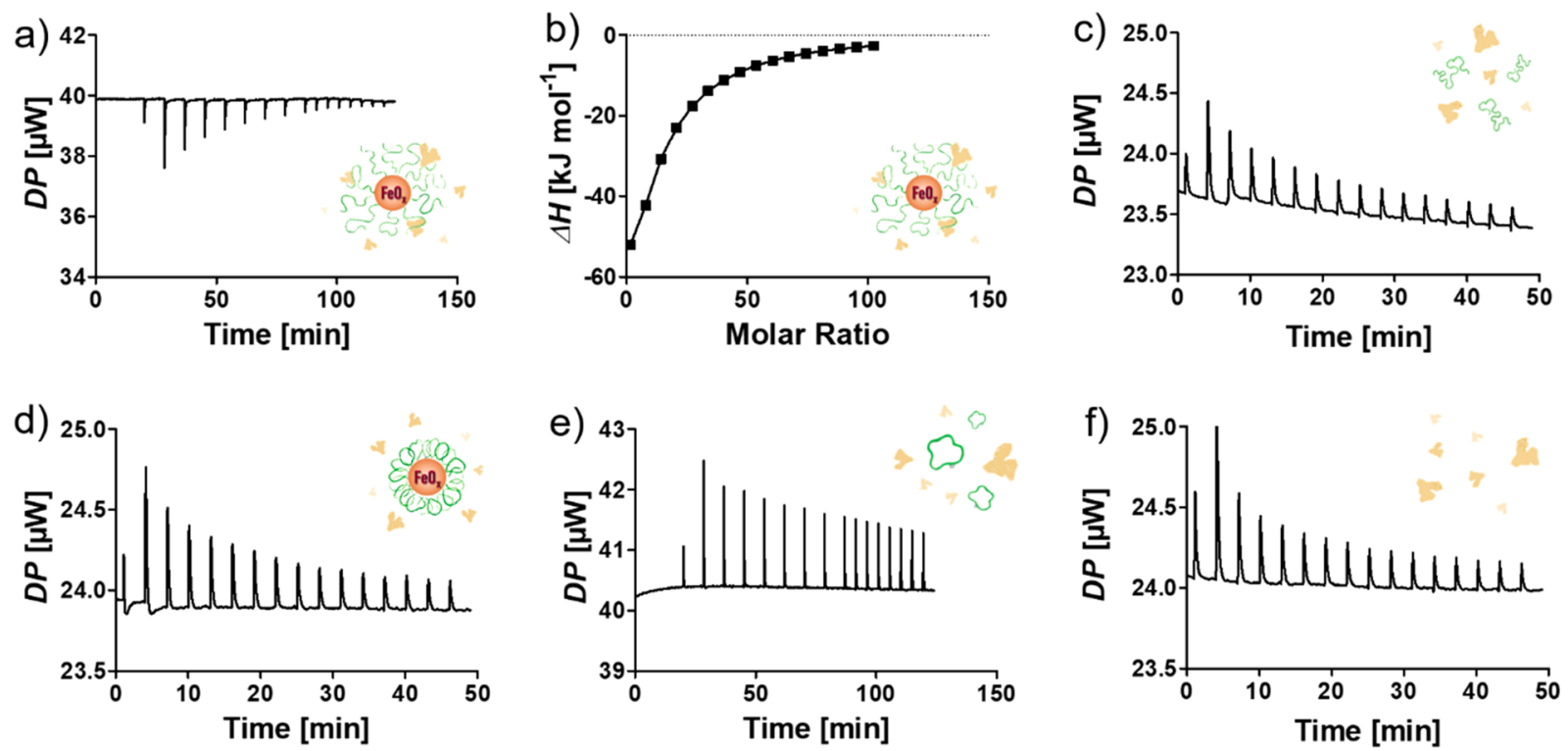

Figure 5. ITC measurements performed on dispersions of L-PEOXA-Fe $\mathrm{O}_{y}$ and C-PEOXA-Fe $\mathrm{O}_{y} \mathrm{NPs}$ subjected to sequential injections of HSA. Differential power (a) and $\Delta H(\mathrm{~b})$ recorded after each injection of HSA into an $800 \mathrm{nM}$ dispersion of L-PEOXA-Fe $\mathrm{O}_{y}$ NPs. A fit with the Wiseman model is highlighted as a solid line. (c) Differential power recorded after each injection of HSA into $200 \mu$ M free L-PEOXA. Differential power recorded after each injection of HSA into (c) $200 \mu \mathrm{M}$ of free L-PEOXA, (d) $800 \mathrm{nM}$ dispersion of C-PEOXA-Fe $\mathrm{O}_{y} \mathrm{NPs}$ (e) $200 \mu \mathrm{M}$ free C-PEOXA, and (f) HEPES buffer solution.

$(\Delta H)$, entropy $(\Delta S)$, and stoichiometry of binding $(n)$ can be obtained. In practice, a Wiseman $c$ value of $c=n[\mathrm{M}] / K_{\mathrm{D}}>2$, where $[\mathrm{M}]$ is the concentration of the NPs, is required to determine accurately all of the above-mentioned parameters. ${ }^{42}$ However, the typical $c$ values achievable for dispersions of NPs are limited by the relatively large size of the interacting objects. High NP concentrations lead to both higher-order colloidal interactions due to the high volume fraction and too high viscosity for accurate measurements. However, Tellinghuisen has demonstrated that a reliable fit for $K_{\mathrm{D}}(\Delta G)$ could be obtained even for values of $c<10^{-4,42}$ and that the analysis at very low $c$ is insensitive to errors in the determination of $n .^{43}$ Unfortunately, the values of $\Delta H$ and $\Delta S$ generated at such low $c$ are characterized by high uncertainty.

In the present study, HSA was added to dispersions of 800 $\mathrm{nM}$ C-PEOXA- $\mathrm{Fe}_{x} \mathrm{O}_{y}$ NPs or L-PEOXA- $\mathrm{Fe}_{x} \mathrm{O}_{y}$ NPs. Any attractive interaction between HSA and the nanoparticles will be due to the presence of the core, as the polymer itself is noninteracting with proteins even at high concentrations. We, therefore, choose the same particle (core) molarity for the comparison. Additional data where the molarity of the polymer was kept constant is provided in the Supporting Information (Figure S12), as the polymer fraction of the sample is higher for C-PEOXA-Fe $\mathrm{O}_{y}$ NPs than for L-PEOXA-Fe $\mathrm{O}_{y}$. The resulting $c$ value for the ITC measurements was $\sim 0.1$ for the interacting NPs. The differential power used to maintain the reference and sample cell in thermal equilibrium for every injection of HSA is shown in Figure 5.

As displayed in Figure 5a, L-PEOXA-Fe $\mathrm{O}_{y}$ NPs display a non-negligible interaction with HSA, as evidenced by the occurrence of exothermic injection peaks, which are evidence of noncovalent protein binding. ${ }^{9}$ This result agrees well with previous findings that described the interaction of NPs functionalized with linear PEG or PEOXA brushes with bovine serum albumin (BSA) and full serum. ${ }^{14}$ The heat of injection decreased upon each subsequent HSA addition, due to the progressive saturation of nonspecific binding sites available on the NPs. The enthalpy corresponding to each injection was calculated by integrating the power over each injection peak after using the fitted offset routine for baseline correction. From the resulting $\Delta H$ versus molar ratio plot (Figure $5 \mathrm{~b}$ ), the values of $n, K_{\mathrm{D}}$, and $\Delta G$ corresponding to LPEOXA- $\mathrm{Fe}_{x} \mathrm{O}_{y}$ NPs interacting with HSA were derived by fitting the data to a Langmuir/Wiseman-type isotherm binding model. ${ }^{44}$ This model is suitable for all samples that have a single type of noninteracting binding site, that is, either a single binding site or $n$ equivalent binding sites.

Although this is a model developed for binding to a single specific protein binding site, it is also a valid assumption in the case of nonspecific protein adsorption on functionalized nanoparticles. The main binding attraction is expected to be through weak van der Waals and double-layer interaction between the protein and the core, overlaid on the brush shell repulsion, leading to similar, multiple noninteracting sites on the particle surface. The chosen model provided a good fit with the values $n=5.1 \pm 5.1, K_{\mathrm{D}}=20.9 \pm 5.8 \mu \mathrm{M}$, and $\Delta G=-26.7$ $\pm 0.1 \mathrm{~kJ} \mathrm{~mol}^{-1}$, which nicely correlate to those previously measured for similar core-brush shell NPs in the presence of BSA. $^{14}$ Thus, a low but quantitative interaction between HSA and L-PEOXA-Fe ${ }_{x} \mathrm{O}_{y}$ NPs is observed as before, ${ }^{14}$ which has to be reconciled with the fact that there is no indication of such corona formation in the DLS experiments (cf. Figures 3 and 4 ). A possible explanation is that the proteins could be interacting with the core from inside the shell. Parak and co-workers previously made a similar observation. ${ }^{20,45}$ The ability of proteins to deform and interact as polymers could facilitate the penetration into linear brush shells. As a comparison, it should be noted that the binding energy is in the range of only one to a few hydrogen bonds per protein, and one should keep in mind that proteins are large macromolecules. This binding energy translates into a long residence time for adsorbed HSA on the particles. Still, it is in a range where reversible and transient binding, and therefore, protein displacement would take place. Although the measured values for $\Delta H$ and $\Delta S$ have 
Scheme 1. (a) L-PEOXA-Fe $\mathrm{O}_{y}$ and (b) C-PEOXA-Fe $\mathrm{O}_{y}$ NPs Show Different Behavior in the Presence of HSA ${ }^{a}$
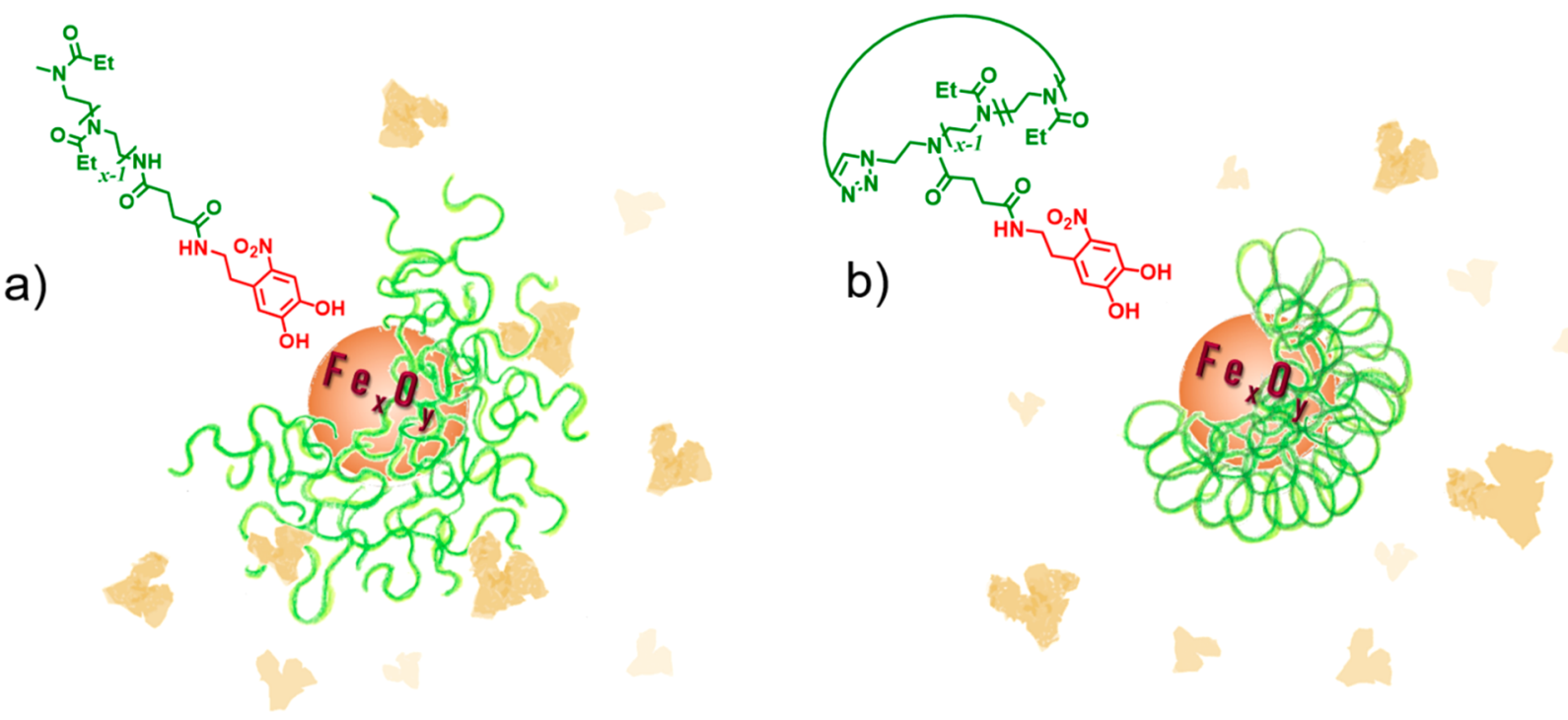

${ }^{a}$ Cyclic PEOXA shells quantitatively prevent the formation of a protein corona. The interaction of proteins with NPs grafted with linear brush shells, presumably inside the shell, cannot be entirely prevented.

high uncertainty, one can also conclude that $\Delta H$ is clearly negative, whereas $\Delta S$ is slightly negative (Table $\mathrm{S} 1$ ). A negative enthalpy change is consistent with a favorable binding interaction of the protein to the nanoparticle surface. The binding energy is large enough to compensate for the marginally negative entropy change, i.e., an increase in the order of the system. As the displacement of water from the brush or the core surface should lead to an increase in entropy, we hypothesize that the increased confinement of the polymer chains and the loss of conformational entropy of the protein upon adsorption make larger contributions than the expulsion of water.

Studying the interaction of HSA with C-PEOXA-Fe $\mathrm{O}_{y} \mathrm{NPs}$ by ITC yielded a drastically different result. Only endothermic peaks were recorded upon the progressive addition of HSA to dispersions of C-PEOXA-Fe $\mathrm{O}_{y} \mathrm{NPs}$ (Figure 5d). Indeed, the result is nearly identical to the injection peaks observed when HSA was added to solutions of "free" linear or cyclic PEOXA with a concentration of $200 \mu \mathrm{M}$, corresponding to the polymer concentration of the nanoparticle dispersions (Figure $5 \mathrm{c}, \mathrm{e}$ ) or pure HEPES buffer (Figure 5f). These results demonstrate that the observed endothermic peaks were derived entirely from the heat of dilution of the proteins in the solution. Thus, cyclic brush-stabilized NPs are inert to protein corona formation. As shown by the control experiments, this result is a property of the brush and not of the cyclization of the polymer. There is no interaction between HSA with neither the linear nor the cyclic free PEOXA, which is expected as the two topologically different polymers have the same molecular weight and chemical properties, such as polarity and solubility.

Through a direct measurement like ITC, we thus proved that a quantitative hindrance of binding interactions between HSA and inorganic NPs could be achieved solely by shifting the topology of the stabilizing polymer brush shell from linear to cyclic. The biopassive character conveyed to the iron oxide cores by the ultradense shell of cyclic PEOXA greatly surpasses the "stealth" properties previously observed for NPs functionalized with linear polymer grafts. The results are superior to those from previous ITC measurements on PEG- and PAOXA- grafted NPs, which display colloidal stability in biofluids and reduced phagocytosis by macrophages. ${ }^{13,21,46}$ HSA is the by far most abundant and one of the most sticky proteins in human blood serum, which makes it likely that this stealth property extends to most proteins. However, ITC and other investigations have shown that protein physicochemical properties, including size, flexibility, and surface charge, influence their adsorption on nanoparticles. ${ }^{17,47,48}$ Future inquiries should address this point by rigorous testing with proteins and biomolecules with diverse biophysical properties.

We believe that the bioinertness displayed by cyclic PEOXA brush shells results from a combination of different effects derived from their intrinsic structure. Cyclic PEOXA adsorbates generate polymer shells with markedly higher grafting density compared to their linear counterparts. Moreover, even when a very high $\sigma$ of $0.5-3$ linear chains $\mathrm{nm}^{-2}$ was reached through the most refined ligand replacement/grafting methods, ${ }^{34,49}$ qualitatively different results in terms of protein interactions and stability in biological media were recorded.

Linear polymer brushes theoretically should provide stronger and longer-range steric repulsion compared to that of cyclic analogues for the same polymer grafting density. ${ }^{39,50}$ However, the radial polymer density profile preventing proteins from approaching the inorganic core is denser and more uniform for cyclic polymer brushes compared to the corresponding linear ones. ${ }^{39,51}$ As a consequence, also highly curved NPs grafted with brushes of cyclic polymers present a very dense and homogeneous polymer interface that efficiently prevents interpenetration by other polymer shells or approaching biomolecules (see Scheme 1). Additionally, cyclic PEOXA brushes do not feature chain ends dangling at the polymer shell-medium interface. The absence of "sticky" chain ends and the complete steric exclusion might be particularly important when the adsorbing molecules are amphiphilic polymers such as proteins, which can partially denature to penetrate the shell and form contact points. These distinctive polymer topology effects cooperatively ensure a much more efficient exclusion of proteins from the volume 
close to the NP core. This hypothesis is in agreement with our AFM measurements ( $c f$. Figure 2) and previous small-angle neutron scattering experiments that showed lower polymer interpenetration into cyclic polymer brushes. ${ }^{51}$

For applications, the chain end group of linear brush shells is used to couple additional functionalities, such as targeting moieties. For cyclic polymers, there is no free end group. Still, the same functionalities can either be randomly (through copolymerization) or specifically (through ring-extension polymerization) introduced at a position in the ring as a protected reactive side group during the polymerization and later converted to the desired biofunctionality. It would also be possible to mix in a minority fraction of bifunctional linear polymer in a majority cyclic polymer shell.

\section{CONCLUSIONS}

In this study, we demonstrated that the formation of a protein corona of HSA could be quantitatively suppressed using cyclic PEOXA brush shells irreversibly grafted on $\mathrm{Fe}_{x} \mathrm{O}_{y}$ NPs. Linear PEOXA grafted in the same way provides colloidally stable NPs with no detectable aggregation with the most abundant and sticky human blood serum protein, albumin, and an excellent reduction in phagocytosis by cells, ${ }^{14,23}$ but they displayed non-negligible interactions with human serum albumin when their dispersions were analyzed by ITC. In contrast, NPs grafted with cyclic PEOXA show no trace of protein binding by ITC as well as no sign of aggregation during DLS measurements, even when the hydration of the shell was reduced by increasing the temperature to the critical solution temperature of the cyclic PEOXA brush.

We observe that the bioinertness by C-PEOXA-Fe $\mathrm{O}_{y} \mathrm{NPs}$ was guaranteed by a sub-10 nm thick cyclic polymer shell, providing core-shell NPs with a much smaller size than organelles, similar to globular proteins. Although several coreshell NP formulations have shown encouraging results when tested within cell cultures, achieving a perfect circulation of NPs in vivo still represents a significant challenge. Hence, we believe that the design of NPs that can altogether avoid protein binding, as demonstrated for C-PEOXA- $\mathrm{Fe}_{x} \mathrm{O}_{y} \mathrm{NPs}$, could realistically improve the performance of synthetic nanomaterials within physiological environments and create a plethora of possible applications in materials science and biotechnology.

\section{EXPERIMENTAL METHODS}

Materials. All chemicals were purchased from Merck and were used as received unless otherwise indicated. (1-Cyano-2-ethoxy-2oxoethylidenaminooxy)dimethylaminomorpholinocarbenium hexafluorophosphate (COMU) was purchased from Carl Roth. 2-Ethyl2-oxazoline (EOXA) was dried over $\mathrm{CaH}_{2}$ before use. Methyl-ptoluenesulfonate was distilled before use.

Synthesis of Iron Oxide Nanoparticle Cores. Superparamagnetic $\mathrm{Fe}_{x} \mathrm{O}_{y}$ NPs were synthesized by thermal decomposition of $\mathrm{Fe}(\mathrm{CO})_{5}$ in dioctyl ether in the presence of oleic acid. ${ }^{34,52}$

Synthesis of L-PEOXA. Two milliliters of EOXA ( $20 \mathrm{mmol})$ was dissolved in $6 \mathrm{~mL}$ of $\mathrm{N}, \mathrm{N}$-dimethylacetamide. Thirty microliters of methyl-p-toluenesulfunoate $(0.2 \mathrm{mmol})$ was added and stirred for 16 $\mathrm{h}$ at $100^{\circ} \mathrm{C}$. The reaction was quenched with $0.1 \mathrm{M} \mathrm{NaOH}(100 \mu \mathrm{L})$ at $70^{\circ} \mathrm{C}$ for $5 \mathrm{~h}$. The polymer was precipitated with $\mathrm{Et}_{2} \mathrm{O}$ and hexane.

Synthesis of C-PEOXA. C-PEOXA was polymerized as previously described and functionalized with nitrodopamine. ${ }^{15,36}$ First, the linear precursor $\alpha$-propargyl- $\omega$-azido PEOXA was obtained using propargyl $p$-toluenesulfonate as an initiator and 2-azidoethylamine as the terminator agent. Intramolecular cyclization of $\alpha$-propargyl- $\omega$-azido PEOXA was performed by $\mathrm{Cu}$-catalyzed Huisgen cycloaddition in water. $\alpha$-Propargyl- $\omega$-azido PEOXA (300 mg, $0.03 \mathrm{mmol}$ ) and sodium ascorbate $(24 \mathrm{mg}, 0.09 \mathrm{mmol})$ were separately dissolved in 170 and $750 \mathrm{~mL}$ of ultrapure water, respectively, in two round-bottom flasks. The two solutions were degassed with $\mathrm{Ar}$ for $30 \mathrm{~min}$. After this time, $\mathrm{CuI}(17 \mathrm{mg}, 0.09 \mathrm{mmol})$ was added to the solution containing sodium ascorbate, and the two flasks were degassed with Ar for an additional $30 \mathrm{~min}$. The degassing process was stopped, and the polymer solution was slowly added to the sodium ascorbate/CuI mixture using a high precision tubing pump (IPC-N4, ISMATEC, Switzerland) at a rate of $45 \mu \mathrm{L} \mathrm{min}^{-1}$ at room temperature while under an Ar atmosphere. When the addition was completed, the reaction was kept under an $\mathrm{Ar}$ atmosphere and stirred for an additional $24 \mathrm{~h}$ prior to volume reduction, filtration $(0.45 \mu \mathrm{m}$ PTFE Chromafil filters), dialysis purification (MWCO $1 \mathrm{kDa}$ ) against (i) 0.1 $\mathrm{g} \mathrm{L}^{-1}$ of ethylenediaminetetraacetic acid solution for $2 \mathrm{~h}$ and (ii) ultrapure water for another $48 \mathrm{~h}$.

Functionalization of L-PEOXA and C-PEOXA with Nitrodopamine (NDA). The procedure for the functionalization of L-PEOXA was exemplarily reported. First, $2.2 \mathrm{~g}$ of L-PEOXA $(0.2 \mathrm{mmol})$ was dissolved in $50 \mathrm{~mL}$ of dry chloroform $\left(\mathrm{CHCl}_{3}\right)$, then $217.7 \mathrm{mg}$ of succinic anhydride $(2.2 \mathrm{mmol})$ and $83.5 \mathrm{mg}$ of 4 -(dimethylamino)pyridine $(0.7 \mathrm{mmol})$ were added. The reaction mixture was refluxed overnight $(16 \mathrm{~h})$. The product was purified by washing it three times with water. A solid was obtained after the solution was dried over $\mathrm{Na}_{2} \mathrm{SO}_{4}$ and the solvent evaporated. This solid was dissolved in $20 \mathrm{~mL}$ of dry DMF. Subsequently, COMU (259.6, $0.6 \mathrm{mmol}), \mathrm{N}, \mathrm{N}$ diisopropylethylamine $(300 \mu \mathrm{L}, 1.7 \mathrm{mmol})$, and NDA $(210 \mathrm{mg}, 0.7$ $\mathrm{mmol}$ ) were added and stirred for $48 \mathrm{~h}$ at room temperature. The product was precipitated with $\mathrm{Et}_{2} \mathrm{O}$ and hexane and further purified by dialysis using membranes with MWCO of $1 \mathrm{kDa}$ for 7 days against ultrapure water.

Functionalization of $\mathrm{Fe}_{x} \mathrm{O}_{y} \mathrm{NPs} . \mathrm{Fe}_{x} \mathrm{O}_{y} \mathrm{NPs}$ were functionalized with L- and C-PEOXA by applying previously described protocols. $^{23,32}$ NDA exhibits high affinity to ferric materials and ensures that the polymers are stably grafted also at high brush densities. ${ }^{32,53}$ The functionalization of $\mathrm{Fe}_{x} \mathrm{O}_{y}$ NPs with L-PEOXA is exemplarily reported. First, $263 \mathrm{mg}$ of wet oleic-acid-coated $\mathrm{Fe}_{x} \mathrm{O}_{y} \mathrm{NPs}$ (core size $8.9 \mathrm{~nm}$, inorganic fraction $32.7 \%$ ) was dissolved in $1 \mathrm{~mL}$ of toluene. One gram of L-PEOXA was dissolved in $12 \mathrm{~mL}$ of DMF. Both solutions were mixed and reacted under ultrasonication for $48 \mathrm{~h}$. The temperature was kept below $30{ }^{\circ} \mathrm{C}$. The particles were precipitated with $\mathrm{Et}_{2} \mathrm{O} /$ hexane (ratio 1:1) and dialyzed against ultrapure water (MWCO $1000 \mathrm{kDa}$ for L-PEOXA, MWCO $300 \mathrm{kDa}$ for C-PEOXA) for 4 days.

Preparation of L-PEOXA/C-PEOXA Shell $\mathrm{Fe}_{x} \mathrm{O}_{y}-$ Core NPs. HEPES buffer $(10 \mathrm{mM})$ was prepared by weighing and dissolving $1.19 \mathrm{~g}$ of HEPES, $4 \mathrm{~g}$ of NaCl, and $0.1 \mathrm{~g}$ of $\mathrm{KCl}$ in $500 \mathrm{~mL}$ of ultrapure water (final volume), yielding final concentrations of $10 \mathrm{mM}$ HEPES, $137 \mathrm{mM} \mathrm{NaCl}$, and $2.7 \mathrm{mM} \mathrm{KCl}$. A few drops of $1 \mathrm{M} \mathrm{NaOH}$ were added to reach a final $\mathrm{pH}$ of 7.4. The buffer was filtered after preparation and stored at $4{ }^{\circ} \mathrm{C}$. PEOXA-functionalized $\mathrm{Fe}_{x} \mathrm{O}_{y}$ NPs were weighed using a Sartorius Secura microbalance and then dissolved at the desired concentration in HEPES buffer. The particles were dissolved in buffer and/or in ultrapure water and were used without filtration.

Nuclear Magnetic Resonance Spectroscopy. ${ }^{1} \mathrm{H}$ NMR measurements were recorded on a Bruker AV III $300 \mathrm{MHz}$ spectrometer.

Size Exclusion Chromatography. SEC was performed on a Malvern Viscotek GPCmax system to determine the relative molecular weight. The setup included three MZ gel SDPlus columns (a precolumn followed by two columns with separation ranges of 10$2000 \mathrm{kDa}$ and 1-40 kDa). For detection, a Knauer Smartline RI detector 2300 was used. As eluent, DMF containing $0.05 \mathrm{M} \mathrm{LiBr}$ was

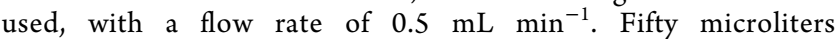
(concentration $=3 \mathrm{~g} \mathrm{~L}^{-1}$ ) of each sample was injected and measured at $60{ }^{\circ} \mathrm{C}$. For the analysis, OminSEC 5.12 software was used. The system was calibrated with polystyrene standards with $M_{\mathrm{n}}=1.5-651$ $\mathrm{kDa}$.

Transmission Electron Micrographs. TEM images were recorded on an FEI Tecnai G2 with $160 \mathrm{kV}$ acceleration voltage on 
carbon-coated grids. The size distribution of each batch of particles was based on the analysis of $>300$ NPs imaged by TEM and calculated using the freeware Pebbles. ${ }^{54}$ For the uranyl acetate staining, mica chips were coated with a $\sim 10 \mathrm{~nm}$ carbon film. A $1 \mathrm{~g} \mathrm{~L}^{-1}$ suspension of PEOXA-functionalized $\mathrm{Fe}_{x} \mathrm{O}_{y}$ NPs was pipetted to the edge of the mica chip so that the suspension floated between mica and carbon film. The mica was transferred to the interface of a $1 \mathrm{wt} \%$ uranyl acetate solution. The carbon film floated, while the mica sank. The carbon film was collected on an empty grid. For the phosphotungstic acid (PTA) staining, first, the grid was treated with plasma to introduce a negative charge on the surface. Three microliters of a $1 \mathrm{~g} \mathrm{~L}^{-1}$ suspension of PEOXA-functionalized $\mathrm{Fe}_{x} \mathrm{O}_{y}$ was incubated for $3 \mathrm{~min}$ on the grid; the excess was removed by filter paper. Afterward, a 1 wt \% solution of PTA at $\mathrm{pH} 7$ was incubated for $1 \mathrm{~min}$. The excess PTA solution was removed with filter paper.

Thermogravimetric Analysis. TGA was recorded on a Mettler Toledo TGA/DSC $\left(80 \mathrm{~mL} \mathrm{~min}{ }^{-1}\right.$ synthetic air, $20 \mathrm{~mL} \mathrm{~min}{ }^{-1}$ nitrogen). The measurements were carried out in a temperature range from 25 to $650{ }^{\circ} \mathrm{C}$ with a heating rate of $10 \mathrm{~K} \mathrm{~min}^{-1}$. The grafting density $(\sigma)$ was calculated from the TGA, GPC, and TEM results using the following formula:

$$
\sigma=\frac{(\% \mathrm{w} / \mathrm{w})_{\text {shell }} \rho_{\text {iron oxide }} V_{\text {core }} N_{\mathrm{A}}}{(\% \mathrm{w} / \mathrm{w})_{\text {core }} M_{\text {polymer }} A_{\text {core }}}
$$

where $(\% \mathrm{w} / \mathrm{w})_{\text {shell }}$ is the percentage of mass loss in TGA for the organic fraction corresponding to the polymer grafted to the $\mathrm{Fe}_{x} \mathrm{O}_{y}$ core, $N_{\mathrm{A}}$ is Avogadro's constant, $\rho_{\text {iron oxide }}$ is the density of iron oxide, $V_{\text {core }}$ is the volume and $A_{\text {core }}$ is the area of the $\mathrm{Fe}_{x} \mathrm{O}_{y}$ core calculated from the diameter of the cores measured by TEM, $M_{\text {polymer }}$ is the molecular weight of the polymer, and $(\% \mathrm{w} / \mathrm{w})_{\text {core }}$ is the residual mass percentage of the inorganic fraction in TGA.

Dynamic Light Scattering. DLS measurements $\left(D_{\mathrm{H}}\right.$, critical flocculation and solution temperature measurements and temperature cycling experiments) were performed in HEPES buffer on a Malvern Zetasizer Nano-ZS (Malvern Instruments Ltd., Worcestershire, UK). Mean values and standard errors of the number-weighted diameter were calculated from three measurements for each temperature step. The CONTIN algorithm was used to extract size distributions from each recording of the correlation curve. Temperature-cycled experiments were performed in the temperature range from 50 to $80{ }^{\circ} \mathrm{C}$ to determine the thermal stability and CST, and additionally in the presence of $0.91 \mathrm{~g} \mathrm{~L}^{-1} \mathrm{HSA}$ from 30 to $62^{\circ} \mathrm{C}$, with a step size of $1{ }^{\circ} \mathrm{C}$. After the temperature was changed, the sample was equilibrated for 2 min and then measured three times. Each reported value is an average of 11 runs. The critical solution temperatures (approximated as the critical flocculation temperatures of the particle dispersions) were determined by the onset of the increase of the hydrodynamic radius versus temperature. Obvious outliers were removed from the data.

Atomic Force Microscopy. Colloidal probe AFM measurements were carried out with an MFP3D (Asylum Research, Oxford Instruments, Santa Barbara, USA). All analyses were performed under $0.1 \mathrm{M}$ pH 6 MOPS buffer at room temperature. The normal $\left(k_{\mathrm{N}}\right)$ spring constant of tipless cantilevers (CSC38/TIPLESS/CR-AU purchased from Mikromasch, Bulgaria) were determined using the thermal noise method. ${ }^{55}$ The colloidal probes were fabricated by gluing a $\sim 20 \mu \mathrm{m}$ in diameter silica microparticle (EKA Chemicals AB, Kromasil R, Sweden) using a custom-made micromanipulator. The nanomechanical properties of L-PEOXA and C-PEOXA brushes were analyzed on flat $\mathrm{TiO}_{2}$-coated silicon substrates (reactive magnetron sputtering, Paul Scherrer Institute, Villigen, Switzerland), which were functionalized with PEOXA brushes following a protocol similar to that applied for the functionalization of $\mathrm{Fe}_{x} \mathrm{O}_{y}$ NPs. L-PEOXA and CPEOXA brushes were compressed by colloidal AFM probes presenting a $20 \mathrm{~nm}$ thick $\mathrm{TiO}_{2}$ layer and functionalized with a topologically identical PEOXA brush, yielding applied force versus separation $(F-S)$ profiles. During these measurements, the $Z$-piezo was ramped over the distance of $2 \mu \mathrm{m}$ with a speed of $0.5 \mathrm{~Hz}$. Imaging of L- and C-PEOXA- $\mathrm{Fe}_{x} \mathrm{O}_{y}$ NPs was carried out using a Bruker Dimension Icon atomic force microscope in tapping mode and employing a silicon cantilever (OMCL-AC160TS, Olympus Microcantilevers, Japan) with a resonance frequency of $\sim 300 \mathrm{kHz}$, and the spring constant was $22.9 \mathrm{~N} \mathrm{~m}^{-1}$.

Variable Angle Spectroscopic Ellipsometry. The dry thickness $\left(d_{\mathrm{dry}}\right)$ of L- and C-PEOXA brushes was measured using a Woolam ellipsometer (J.A. Woollam Co. USA). $\Psi$ and $\Delta$ were recorded as a function of wavelength (included between 350 and $800 \mathrm{~nm}$ ) and subsequently analyzed with CompleteEASE software package (J.A. Woollam Co. USA). Fitting of the obtained $\Psi$ and $\Delta$ values was carried out by applying a layered model, with bulk dielectric functions for $\mathrm{Si}, \mathrm{SiO}_{2}$, and $\mathrm{TiO}_{2}$. PEOXA brushes were analyzed by applying a Cauchy model: $n=A+B \lambda^{-2}$, where $n$ is the refractive index, $\lambda$ is the wavelength, and the coefficients $A$ and $B$ correspond to 1.45 and 0.01 $\mathrm{nm}^{2}$, respectively.

The grafting density $(\sigma)$ of L- and C-PEOXA brushes, expressed as [chains $\mathrm{nm}^{-2}$ ], was calculated using the equation $\sigma=\rho d_{\mathrm{dry}} N_{\mathrm{A}} M_{\mathrm{n}}{ }^{-1}$, where $\rho$ is the density of the dry polymer layer $\left(1.14 \mathrm{~g} \mathrm{~cm}^{-3}\right), d_{\text {dry }}$ is the dry thickness measured by VASE, $N_{\mathrm{A}}$ is Avogadro's number, and $M_{\mathrm{n}}$ is the average molar mass of the adsorbate measured by SEC.

Response to Sequential Addition of HSA to Core-Shell Nanoparticles. PEOXA-coated $\mathrm{Fe}_{x} \mathrm{O}_{y}$ NPs were dispersed in HEPES buffer, reaching a concentration of $0.5 \mathrm{~g} \mathrm{~L}^{-1}$. HSA was dissolved in HEPES buffer to a concentration of $10 \mathrm{~g} \mathrm{~L}^{-1}$. Five microliters of HSA solution was added to $500 \mu \mathrm{L}$ of nanoparticle dispersion and incubated for $10 \mathrm{~min}$ at room temperature. After incubation, the hydrodynamic size distribution of the dispersion was measured using a Malvern Zetasizer Nano-ZS. The HSA concentration was increased stepwise to a value of $0.9 \mathrm{~g} \mathrm{~L}^{-1}$.

Isothermal Titration Calorimetry. ITC measurements were performed at $25{ }^{\circ} \mathrm{C}$ with a Malvern MicroCal PEAQ-ITC Automated ITC. All solutions were degassed and filtered through a $200 \mathrm{~nm}$ syringe filter. The measurement cell was filled with $800 \mathrm{nM}$ of CPEOXA $\mathrm{Fe}_{x} \mathrm{O}_{y}$ NPs or C-PEOXA $\mathrm{Fe}_{x} \mathrm{O}_{y}$ NPs dispersion. Next, 526 $\mu \mathrm{M}$ of HSA in HEPES buffer was loaded into the ITC syringe and titrated 16 times to the particle dispersion. The stirrer speed was set to $600 \mathrm{rpm}$. The titration volume was adjusted to $2.5 \mu \mathrm{L}$, except for the first injection, where the volume was set to $0.2 \mu \mathrm{L}$. For control experiments, buffer-buffer, protein-buffer, and buffer-free polymer titrations were performed and recorded. The first injection was ignored for the fitting of the enthalpy per injection data for L-PEOXA $\mathrm{Fe}_{x} \mathrm{O}_{y}$ NPs. As the fitting model, "one set of sites" was used (corresponding to the Langmuir/Wiseman model). Baseline correction was done using the fitted offset routine, which estimates and subtracts the heat of dilution from the average of the converging injection enthalpies at the end of a titration curve.

\section{ASSOCIATED CONTENT}

\section{Supporting Information}

The Supporting Information is available free of charge at https://pubs.acs.org/doi/10.1021/acsnano.0c02358.

Additional experimental description of the colloidal stability testing, chemical schemes (Scheme S1), NMR (Figures S1-S4), FTIR (Figure S5), and SEC (Figure S6) characterization of the polymer, TEM and histograms for the core-sizing (Figure S7), DLS histograms of the colloidal stability testing under heating (Figure S8), TGA of polymer-grafted nanoparticles (Figure S9), example DLS correlation curves (Figure S10), DLS histograms of nanoparticles exposed to a large range of different HSA concentrations (Figure S11), ITC comparison of nanoparticle interaction with HSA at constant polymer concentration (Figure S12), and thermodynamic parameters fitted for the interaction between L-PEOXA-FexOy and HSA measured by ITC (Table S1) (PDF) 


\section{AUTHOR INFORMATION}

\section{Corresponding Authors}

Edmondo M. Benetti - Polymer Surfaces Group, Laboratory for Surface Science and Technology, Department of Materials, ETH Zürich, CH-8093 Zürich, Switzerland; (1) orcid.org/ 0000-0002-5657-5714; Email: edmondo.benetti@ mat.ethz.ch

Erik Reimhult - Institute for Biologically Inspired Materials, Department of Nanobiotechnology, University of Resources and Life Sciences, A-1190 Vienna, Austria; 이이.org/00000003-1417-5576; Email: erik.reimhult@boku.ac.at

\section{Authors}

Martina Schroffenegger - Institute for Biologically Inspired Materials, Department of Nanobiotechnology, University of Resources and Life Sciences, A-1190 Vienna, Austria

Nikolaus S. Leitner - Institute for Biologically Inspired Materials, Department of Nanobiotechnology, University of Resources and Life Sciences, A-1190 Vienna, Austria

Giulia Morgese - Polymer Surfaces Group, Laboratory for Surface Science and Technology, Department of Materials, ETH Zürich, CH-8093 Zürich, Switzerland

Shivaprakash N. Ramakrishna - Polymer Surfaces Group, Laboratory for Surface Science and Technology, Department of Materials, ETH Zürich, CH-8093 Zürich, Switzerland

Max Willinger - Institute for Biologically Inspired Materials, Department of Nanobiotechnology, University of Resources and Life Sciences, A-1190 Vienna, Austria

Complete contact information is available at: https://pubs.acs.org/10.1021/acsnano.0c02358

\section{Author Contributions}

${ }^{\S}$ M.S. and N.S.L. contributed equally.

\section{Notes}

The authors declare no competing financial interest.

\section{ACKNOWLEDGMENTS}

The research presented in that paper was funded by the Austrian Science Fund (FWF) Grant No. I3064. This project was supported by EQ-BOKU VIBT GmbH through access to DSC, ITC, and TGA at the BOKU Core Facility for Biomolecular and Cellular Analysis, VIBT Extremophile Center, and the VIBT Imaging Center, respectively. The authors thank Andrea Lassenberger and Cindy Dreier for the support with the TEM imaging.

\section{REFERENCES}

(1) Shemetov, A. A.; Nabiev, I.; Sukhanova, A. Molecular Interaction of Proteins and Peptides with Nanoparticles. ACS Nano 2012, 6, $4585-4602$.

(2) Nel, A. E.; Mädler, L.; Velegol, D.; Xia, T.; Hoek, E. M. V.; Somasundaran, P.; Klaessig, F.; Castranova, V.; Thompson, M. Understanding Biophysicochemical Interactions at the Nano-Bio Interface. Nat. Mater. 2009, 8, 543-557.

(3) Monopoli, M. P.; Åberg, C.; Salvati, A.; Dawson, K. A. Biomolecular Coronas Provide the Biological Identity of Nanosized Materials. Nat. Nanotechnol. 2012, 7, 779-786.

(4) Corbo, C.; Molinaro, R.; Parodi, A.; Toledano Furman, N. E.; Salvatore, F.; Tasciotti, E. The Impact of Nanoparticle Protein Corona on Cytotoxicity, Immunotoxicity and Target Drug Delivery. Nanomedicine 2016, 11, 81-100.

(5) Lynch, I.; Cedervall, T.; Lundqvist, M.; Cabaleiro-Lago, C.; Linse, S.; Dawson, K. A. The Nanoparticle-Protein Complex as a
Biological Entity; a Complex Fluids and Surface Science Challenge for the 21st Century. Adv. Colloid Interface Sci. 2007, 134-135, 167-174.

(6) Reimhult, E. Nanoparticle Interactions with Blood Proteins and What It Means: A Tutorial Review. Blood and Genomics 2019, 3, 7387.

(7) Bekdemir, A.; Liao, S.; Stellacci, F. On the Effect of Ligand Shell Heterogeneity on Nanoparticle/Protein Binding Thermodynamics. Colloids Surf., B 2019, 174, 367-373.

(8) Simonelli, F.; Rossi, G.; Monticelli, L. Role of Ligand Conformation on Nanoparticle-Protein Interactions. J. Phys. Chem. B 2019, 123, 1764-1769.

(9) Huang, R.; Carney, R. P.; Stellacci, F.; Lau, B. L. T. ProteinNanoparticle Interactions: The Effects of Surface Compositional and Structural Heterogeneity Are Scale Dependent. Nanoscale 2013, 5, $6928-6935$

(10) Huang, R.; Carney, R. P.; Ikuma, K.; Stellacci, F.; Lau, B. L. T. Effects of Surface Compositional and Structural Heterogeneity on Nanoparticle-Protein Interactions: Different Protein Configurations. ACS Nano 2014, 8, 5402-5412.

(11) Moyano, D. F.; Ray, M.; Rotello, V. M. Nanoparticle-Protein Interactions: Water Is the Key. MRS Bull. 2014, 39, 1069-1073.

(12) Moyano, D. F.; Saha, K.; Prakash, G.; Yan, B.; Kong, H.; Yazdani, M.; Rotello, V. M. Fabrication of Corona-Free Nanoparticles with Tunable Hydrophobicity. ACS Nano 2014, 8, 6748-6755.

(13) Walkey, C. D.; Olsen, J. B.; Guo, H.; Emili, A.; Chan, W. C. W. Nanoparticle Size and Surface Chemistry Determine Serum Protein Adsorption and Macrophage Uptake. J. Am. Chem. Soc. 2012, 134, 2139-2147.

(14) Gal, N.; Schroffenegger, M.; Reimhult, E. Stealth Nanoparticles Grafted with Dense Polymer Brushes Display Adsorption of Serum Protein Investigated by Isothermal Titration Calorimetry. J. Phys. Chem. B 2018, 122, 5820-5834.

(15) Morgese, G.; Shirmardi Shaghasemi, B.; Causin, V.; ZenobiWong, M.; Ramakrishna, S. N.; Reimhult, E.; Benetti, E. M. NextGeneration Polymer Shells for Inorganic Nanoparticles Are Highly Compact, Ultra-Dense, and Long-Lasting Cyclic Brushes. Angew. Chem., Int. Ed. 2017, 56, 4507-4511.

(16) Ke, P. C.; Lin, S.; Parak, W. J.; Davis, T. P.; Caruso, F. A Decade of the Protein Corona. ACS Nano 2017, 11, 11773-11776.

(17) Cedervall, T.; Lynch, I.; Lindman, S.; Berggård, T.; Thulin, E.; Nilsson, H.; Dawson, K. A.; Linse, S. Understanding the Nanoparticle-Protein Corona Using Methods to Quntify Exchange Rates and Affinities of Proteins for Nanoparticles. Proc. Natl. Acad. Sci. U. S. A. 2007, 104, 2050-2055.

(18) Amstad, E.; Textor, M.; Reimhult, E. Stabilization and Functionalization of Iron Oxide Nanoparticles for Biomedical Applications. Nanoscale 2011, 3, 2819-2843.

(19) Lassenberger, A.; Scheberl, A.; Stadlbauer, A.; Stiglbauer, A.; Helbich, T.; Reimhult, E. Individually Stabilized, Superparamagnetic Nanoparticles with Controlled Shell and Size Leading to Exceptional Stealth Properties and High Relaxivities. ACS Appl. Mater. Interfaces 2017, 9, 3343-3353.

(20) Pelaz, B.; del Pino, P.; Maffre, P.; Hartmann, R.; Gallego, M.; Rivera-Fernández, S.; de la Fuente, J. M.; Nienhaus, G. U.; Parak, W. J. Surface Functionalization of Nanoparticles with Polyethylene Glycol: Effects on Protein Adsorption and Cellular Uptake. ACS Nano 2015, 9, 6996-7008.

(21) Schöttler, S.; Becker, G.; Winzen, S.; Steinbach, T.; Mohr, K.; Landfester, K.; Mailänder, V.; Wurm, F. R. Protein Adsorption Is Required for Stealth Effect of Poly(Ethylene Glycol)- and Poly(Phosphoester)-Coated Nanocarriers. Nat. Nanotechnol. 2016, 11, 372-377.

(22) Gal, N.; Lassenberger, A.; Herrero-Nogareda, L.; Scheberl, A.; Charwat, V.; Kasper, C.; Reimhult, E. Interaction of Size-Tailored PEGylated Iron Oxide Nanoparticles with Lipid Membranes and Cells. ACS Biomater. Sci. Eng. 2017, 3, 249-259.

(23) Kurzhals, S.; Gal, N.; Zirbs, R.; Reimhult, E. Controlled Aggregation and Cell Uptake of Thermoresponsive Polyoxazoline- 
Grafted Superparamagnetic Iron Oxide Nanoparticles. Nanoscale 2017, 9, 2793-2805.

(24) Honda, S.; Yamamoto, T.; Tezuka, Y. Tuneable Enhancement of the Salt and Thermal Stability of Polymeric Micelles by Cyclized Amphiphiles. Nat. Commun. 2013, 4, 1574.

(25) Heo, K.; Kim, Y. Y.; Kitazawa, Y.; Kim, M.; Jin, K. S.; Yamamoto, T.; Ree, M. Structural Characteristics of Amphiphilic Cyclic and Linear Block Copolymer Micelles in Aqueous Solutions. ACS Macro Lett. 2014, 3, 233-239.

(26) Hadziioannou, G.; Cotts, P. M.; ten Brinke, G.; Han, C. C.; Lutz, P.; Strazielle, C.; Rempp, P.; Kovacs, A. J. Thermodynamic and Hydrodynamic Properties of Dilute Solutions of Cyclic and Linear Polystyrenes. Macromolecules 1987, 20, 493-497.

(27) Satokawa, Y.; Shikata, T.; Tanaka, F.; Qiu, X.; Winnik, F. M. Hydration and Dynamic Behavior of a Cyclic Poly(N-Isopropylacrylamide) in Aqueous Solution: Effects of the Polymer Chain Topology. Macromolecules 2009, 42, 1400-1403.

(28) Morgese, G.; Trachsel, L.; Romio, M.; Divandari, M.; Ramakrishna, S. N.; Benetti, E. M. Topological Polymer Chemistry Enters Surface Science: Linear versus Cyclic Polymer Brushes. Angew. Chem. 2016, 128, 15812-15817.

(29) Verbraeken, B.; Monnery, B. D.; Lava, K.; Hoogenboom, R. The Chemistry of Poly(2-Oxazoline)S. Eur. Polym. J. 2017, 88, 451469.

(30) Laurent, B. A.; Grayson, S. M. An Efficient Route to WellDefined Macrocyclic Polymers via "Click" Cyclization. J. Am. Chem. Soc. 2006, 128, 4238-4239.

(31) Laurent, B. A.; Grayson, S. M. Synthetic Approaches for the Preparation of Cyclic Polymers. Chem. Soc. Rev. 2009, 38, 22022213.

(32) Amstad, E.; Gillich, T.; Bilecka, I.; Textor, M.; Reimhult, E. Ultrastable Iron Oxide Nanoparticle Colloidal Suspensions Using Dispersants with Catechol-Derived Anchor Groups. Nano Lett. 2009, 9, 4042-4048.

(33) Morgese, G.; Causin, V.; Maggini, M.; Corrà, S.; Gross, S.; Benetti, E. M. Ultrastable Suspensions of Polyoxazoline-Functionalized ZnO Single Nanocrystals. Chem. Mater. 2015, 27, 2957-2964.

(34) Lassenberger, A.; Bixner, O.; Gruenewald, T.; Lichtenegger, H.; Zirbs, R.; Reimhult, E. Evaluation of High-Yield Purification Methods on Monodisperse PEG-Grafted Iron Oxide Nanoparticles. Langmuir 2016, 32, 4259-4269.

(35) Schroffenegger, M.; Reimhult, E. Thermoresponsive Core-Shell Nanoparticles: Does Core Size Matter? Materials 2018, 11, 1654

(36) Schroffenegger, M.; Zirbs, R.; Kurzhals, S.; Reimhult, E. The Role of Chain Molecular Weight and Hofmeister Series Ions in Thermal Aggregation of Poly(2-Isopropyl-2-Oxazoline) Grafted Nanoparticles. Polymers (Basel, Switz.) 2018, 10, 451.

(37) Zirbs, R.; Lassenberger, A.; Vonderhaid, I.; Kurzhals, S.; Reimhult, E. Melt-Grafting for the Synthesis of Core-Shell Nanoparticles with Ultra-High Dispersant Density. Nanoscale 2015, 7, 11216-11225.

(38) Edwards, C. J. C.; Richards, R. W.; Stepto, R. F. T.; Dodgson, K.; Higgins, J. S.; Semlyen, J. A. Studies of Cyclic and Linear Poly(Dimethyl Siloxanes): 14. Particle Scattering Functions. Polymer 1984, 25, 365-368.

(39) He, S.-Z.; Holger, M.; Su, C.-F.; Wu, C.-X. Static and Dynamic Properties of Grafted Ring Polymer: Molecular Dynamics Simulation. Chin. Phys. B 2013, 22, No. 016101.

(40) Divandari, M.; Morgese, G.; Trachsel, L.; Romio, M.; Dehghani, E. S.; Rosenboom, J.-G.; Paradisi, C.; Zenobi-Wong, M.; Ramakrishna, S. N.; Benetti, E. M. Topology Effects on the Structural and Physicochemical Properties of Polymer Brushes. Macromolecules 2017, 50, 7760-7769.

(41) Cedervall, T.; Lynch, I.; Lindman, S.; Berggård, T.; Thulin, E.; Nilsson, H.; Dawson, K. A.; Linse, S. Understanding the Nanoparticle-Protein Corona Using Methods to Quntify Exchange Rates and Affinities of Proteins for Nanoparticles. Proc. Natl. Acad. Sci. U. S. A. 2007, 104, 2050-2055.
(42) Tellinghuisen, J. Isothermal Titration Calorimetry at Very Low c. Anal. Biochem. 2008, 373, 395-397.

(43) Tellinghuisen, J. Optimizing Experimental Parameters in Isothermal Titration Calorimetry. J. Phys. Chem. B 2005, 109, 20027-20035.

(44) Wiseman, T.; Williston, S.; Brandts, J. F.; Lin, L.-N. Rapid Measurement of Binding Constants and Heats of Binding Using a New Titration Calorimeter. Anal. Biochem. 1989, 179, 131-137.

(45) Carril, M.; Padro, D.; Del Pino, P.; Carrillo-Carrion, C.; Gallego, M.; Parak, W. J. In Situ Detection of the Protein Corona in Complex Environments. Nat. Commun. 2017, 8, 1542.

(46) Saptarshi, S. R.; Duschl, A.; Lopata, A. L. Interaction of Nanoparticles with Proteins: Relation to Bio-Reactivity of the Nanoparticle. J. Nanobiotechnol. 2013, 11, 26.

(47) Prozeller, D.; Morsbach, S.; Landfester, K. Isothermal Titration Calorimetry as a Complementary Method for Investigating Nanoparticle-Protein Interactions. Nanoscale 2019, 11, 19265-19273.

(48) Marichal, L.; Degrouard, J.; Gatin, A.; Raffray, N.; Aude, J. C.; Boulard, Y.; Combet, S.; Cousin, F.; Hourdez, S.; Mary, J.; Renault, J. P.; Pin, S. From Protein Corona to Colloidal Self-Assembly: The Importance of Protein Size in Protein-Nanoparticle Interactions. Langmuir 2020, 36, 8218-8230.

(49) Zirbs, R.; Lassenberger, A.; Vonderhaid, I.; Kurzhals, S.; Reimhult, E. Melt-Grafting for the Synthesis of Core-Shell Nanoparticles with Ultra-High Dispersant Density. Nanoscale 2015, 7, 11216-11225.

(50) Zhulina, E. B.; Leermakers, F. A. M.; Borisov, O. V. Brushes of Cycled Macromolecules: Structure and Lubricating Properties. Macromolecules 2016, 49, 8758-8767.

(51) Higgins, J. S.; Dodgson, K.; Semlyen, J. A. Studies of Cyclic and Linear Poly(Dimethyl Siloxanes): 3. Neutron Scattering Measurements of the Dimensions of Ring and Chain Polymers. Polymer 1979, 20, 553-558.

(52) Hyeon, T.; Lee, S. S.; Park, J.; Chung, Y.; Na, H. B. Synthesis of Highly Crystalline and Monodisperse Maghemite Nanocrystallites without a Size-Selection Process. J. Am. Chem. Soc. 2001, 123, 12798-12801.

(53) Yuen, A. K. L.; Hutton, G. a.; Masters, A. F.; Maschmeyer, T. The Interplay of Catechol Ligands with Nanoparticulate Iron Oxides. Dalton Trans. 2012, 41, 2545-2559.

(54) Mondini, S.; Ferretti, A. M.; Puglisi, A.; Ponti, A. Pebbles and PebbleJuggler: Software for Accurate, Unbiased, and Fast Measurement and Analysis of Nanoparticle Morphology from Transmission Electron Microscopy (TEM) Micrographs. Nanoscale 2012, 4, 53565372.

(55) Hutter, J. L.; Bechhoefer, J. Calibration of Atomic-Force Microscope Tips. Rev. Sci. Instrum. 1993, 64, 1868-1873. 